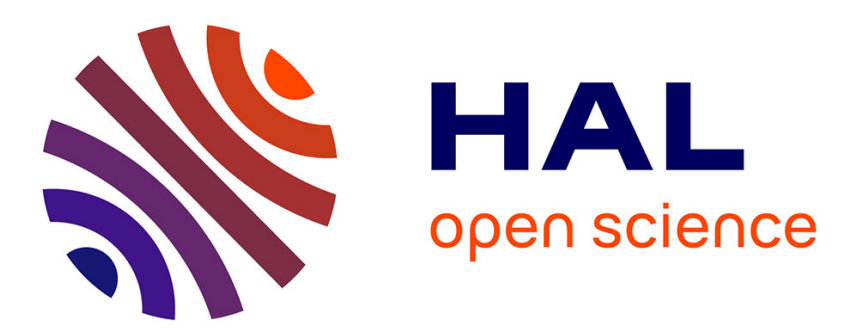

\title{
Can We Really Detect Cavities Using Seismic Surface Wave?
}

\author{
Adnand Bitri, Kevin Samyn, Christophe Filippi
}

\section{To cite this version:}

Adnand Bitri, Kevin Samyn, Christophe Filippi. Can We Really Detect Cavities Using Seismic Surface Wave?. 22nd European Meeting of Environmental and Engineering Geophysics: Near Surface Geoscience 2016, Sep 2016, Barcelone, Spain. hal-01371628

\section{HAL Id: hal-01371628 https://hal-brgm.archives-ouvertes.fr/hal-01371628}

Submitted on 26 Sep 2016

HAL is a multi-disciplinary open access archive for the deposit and dissemination of scientific research documents, whether they are published or not. The documents may come from teaching and research institutions in France or abroad, or from public or private research centers.
L'archive ouverte pluridisciplinaire HAL, est destinée au dépôt et à la diffusion de documents scientifiques de niveau recherche, publiés ou non, émanant des établissements d'enseignement et de recherche français ou étrangers, des laboratoires publics ou privés. 


\section{Can We Really Detect Cavities Using Seismic Surface Wave? \\ NEAR SURFACE GEOSCIENCE - Barcelone, (04-08/09/2016) \\ Bitri A., Samyn K., Filippi C.}

\section{Introduction}

Shallow cavities, such as karstic caves in carbonate bedrock, near-surface underground mine workings and tunnels, constitute serious hazards for people and existing constructions due to the risk of collapse and subsidence. This phenomena is growing fast with climate change involving damages to buildings and increasing urban development costs. Karstic features, voids, surficial dissolution, alteration and unconsolidated material are thus major challenges for geophysical methods which could play a major role for their detection. Recent investigations have reported good results for cavity imaging using surface wave seismic methods (Sloan et al. 2015, Samyn et al., 2013, Leparoux et al., 2000, Nasseri-Moghaddam et al. 2005, Gucunski et al., 1996, Park et al. 1996). But in spite of successful case histories, business as usual void detection is still challenging due to the complexity of near surface materials and probably the limited resolution of geophysical methods.

The propagation of Rayleigh waves in homogeneous layered media is well understood and has been addressed in depth by several authors (Thomson 1950, Haskel 1953, Graf 1975).

The derivation of analytical solutions for the scattering of Rayleigh waves around heterogeneities is complicated and researchers often perform experimental tests or develop numerical models to study this problem (Gelis et al. 2005, Gucunski et al. 1996). These numerical studies have shown reflections from the heterogeneities (even in the cavities) and perturbations in the dispersion curves.

Leparoux et al. (2000) applied the MASW test to locate two cavities: masonry at $3.0 \mathrm{~m}$ below the ground surface, and the other one embedded at about $8.0 \mathrm{~m}$ beneath the surface, without masonry. $\mathrm{Xia}$ at al. (2007) demonstrated using 2-D surface wave modeling that the diffractions due to a void on a homogenous half space were Raleigh-wave diffractions because of their amplitude, velocity, and frequency. They derived a travel-time equation of surface wave diffractions based on properties of surface wave and solved this equation for a phase velocity and depth to a void. Sloan et al. (2015) demonstrated the capability of using P-wave diffraction and surface wave backscatter techniques to detect subterranean tunnels.

Despite these convincing arguments, we have been recently confronted to disheartening results leading us to the question: Can we really detect cavities using seismic surface wave?

The objective of this study is to pose the problem for understanding interaction between a cavity and a Rayleigh wave by measuring the wave field in surface on the roof and on the floor of a known cavity. For addressing this issue, we have focussed on a study area located in Souzay-Champigny, France. This consists of an abandoned underground quarry network in cretaceous chalky limestone (Bitri et al. 2014). We have chosen these cavities because they are accessible underground and partly mapped.

\section{Data acquisition and processing}

The cavity dimensions are: $55 \mathrm{~m}$ long, $7 \mathrm{~m}$ wide and $3.2 \mathrm{~m}$ high and is located at about $4 \mathrm{~m}$ below the ground surface. The first seismic acquisition geometry consisted of 3 different lines along the axis of the gallery: in surface, on the roof and on the floor (Fig. 1).

The first step in processing of surface wave consists of determining the dispersion curve, i.e. the phase velocity variation versus frequency. It is calculated by using the slant-stack method in a common-shot gather, followed by a 1D Fourier transform over the intercept time. Each dispersion curve (Fig. 2) was individually inverted into a depth versus shear-wave velocity profile. The linearized iterative leastsquares technique used here is adapted from Hermann (1987). 2D contour plot of the shear-wave velocity field was produced by gathering all the $1 \mathrm{D}$ velocity profiles into sequential order (Fig. 3). In the literature of shallow seismic methods, it is accepted that the bedrock is usually associated with high $\mathrm{S}$ velocity gradient whereas fractures zone and voids by low velocity zone. The results of this study show a low S-velocity layer $(250-300 \mathrm{~m} / \mathrm{s})$ with $\sim 2 \mathrm{~m}$ thick over a cretaceous chalky limestone of a velocity between $600-700 \mathrm{~m} / \mathrm{s}$. The S-velocity section recorded on the surface and the one 
recorded on the roof exhibit roughly same results. On both, the low velocity zone, indicating the presence of the cavity, is not observed.
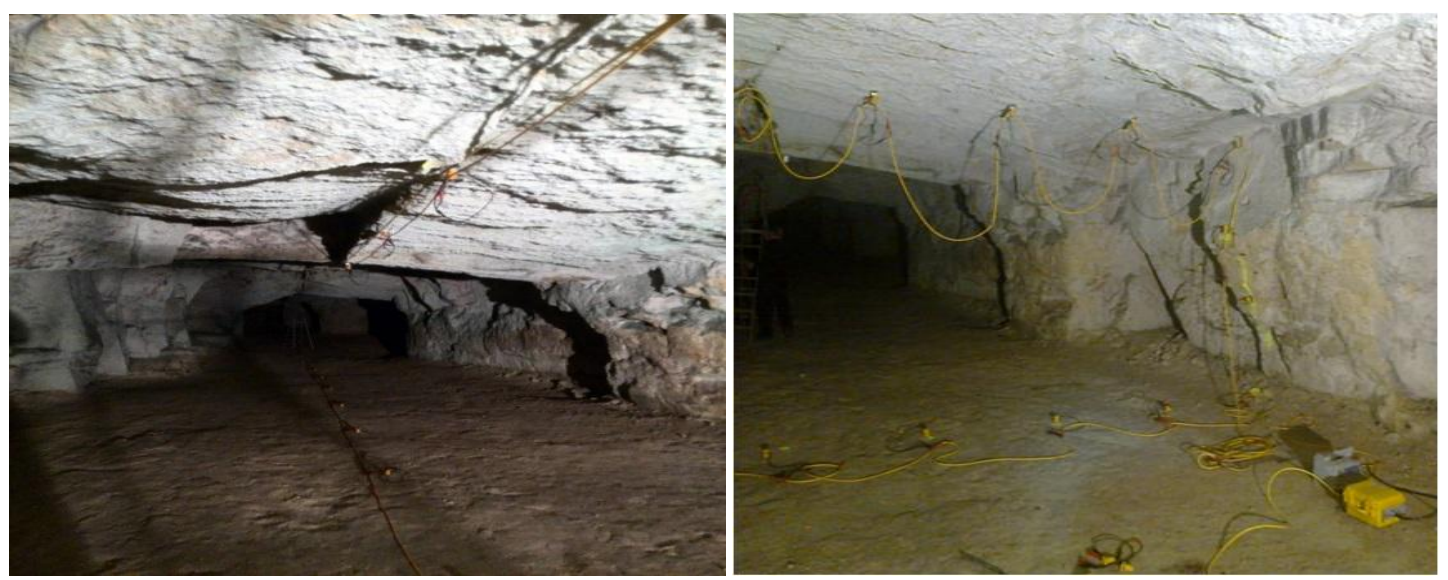

Figure 1 Images of the inside of the gallery showing the acquisition geometries
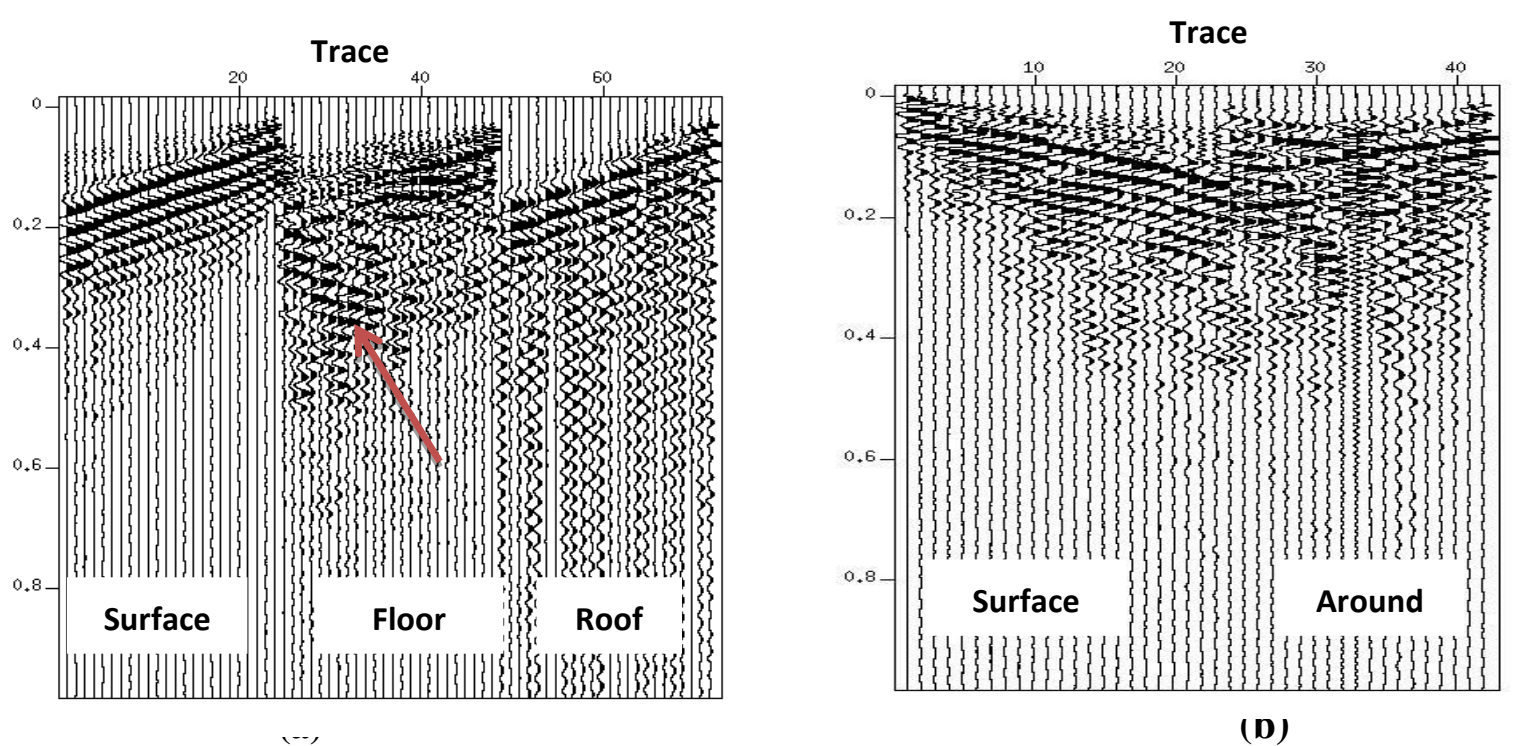

(D)

Figure 2 Example of field shot gather a- row data recorded with the geophones on surface, roof and floor: b- row data recorded on surface and around the gallery.

Each line consists of twenty-four $10 \mathrm{~Hz}$-single-component vertical geophones at $2 \mathrm{~m}$ intervals. Three 24 channels Geodes from Geometrics were used to record and stack vertically four $10 \mathrm{~kg}$ hammer impacts in surface. The distance between the sources was $2 \mathrm{~m}$. Data were recorded at a sample rate of $0.5 \mathrm{~ms}$ during 1 second. An aeration pit close to the site has been used for surface-cavity communication (time break, streamer connection etc.). A special steel plate is manufactured for clipping the geophones to the roof. The second acquisition geometry consisted of one line in surface perpendicular to the gallery with 24 vertical geophones at $2 \mathrm{~m}$ intervals followed by another one with geophones placed along the perimeter of the gallery at $1 \mathrm{~m}$ intervals. As shown in the figure 2 the raw traces show clear developed surface waves. A back retrograde energy is recorded by the floor 
geophones. This is probably due to the wave traveling back from the end of gallery and recorded by the floor geophones. The surface data is not disturbed by the presence of the cavity.

Regarding the acquisition geometry perpendicular to the gallery, we hope to find $\mathrm{P}$ waves diffractions and backscattered surface waves. In order to enhance the backscattered energy stemming from the subsurface gallery, the data are processed as follow: imaging the dispersion for each shot gather, applying a dynamic linear moveout (DLMO) to the shot gather in order to flatten the direct surface wave, extracting the guided waves from the shot gather using zero-lag Karhunen-Loeve transform, and then subtracting them from the original data (Bitri and Grandjean 2006). The shot gathers are sorted and stacked into common receiver gathers (Fig. 4). Normally, stacking procedure improve backscatter energy if presents in the data. Backscatter energy appears as the highest amplitude linear sloping event in the opposite direction from the forward energy (Sloan et al. 2015). In our case, the backscattered events should be around the middle of the stacked section. These events are not observed on the stacked seismic section. It seems that the surface waves travel over and above the cavity without losing energy by diffraction and backscattering.
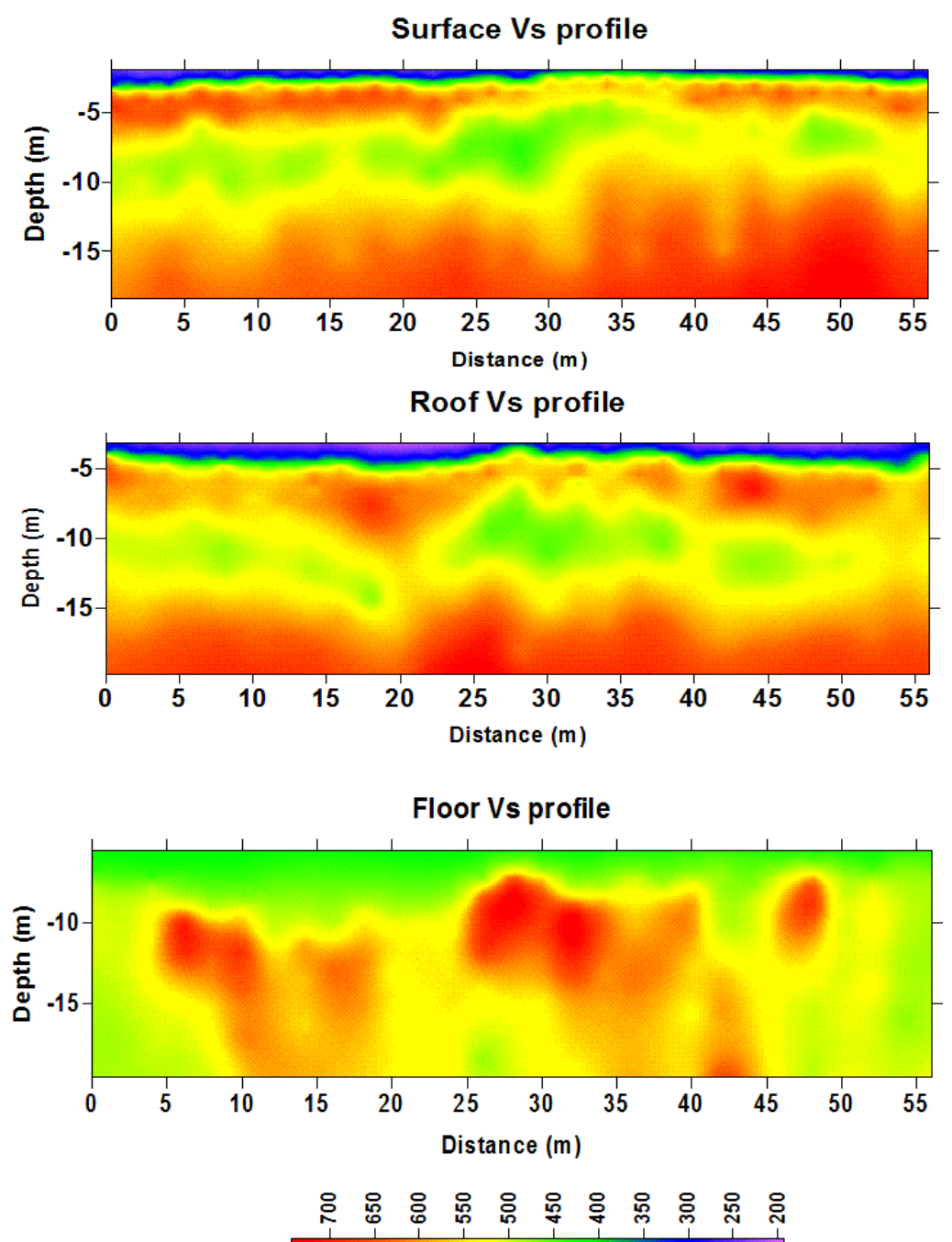

Figure 3- Plots showing the 2D S-velocities from the data on the surface, on the roof and on the floor 


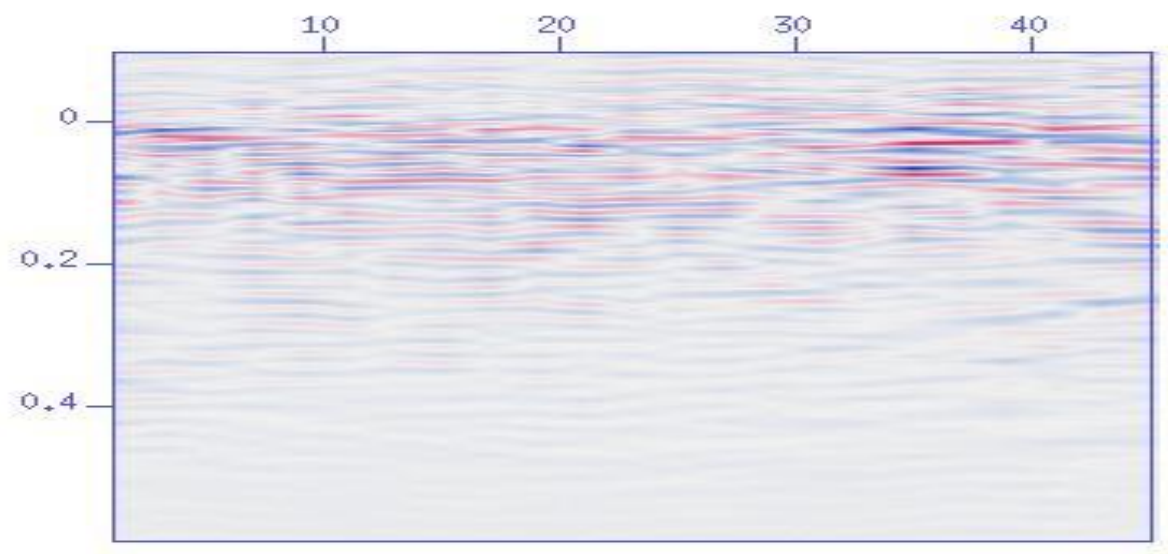

Figure 4- Stacked section without backscatter anomalies. Gallery is located in the middle of the section

\section{Conclusions}

Cavity detection continues to be a challenging geophysical problem. Based on a large contrast in material properties and seismic waves velocities between an air filled cavity and the surrounding medium, the seismic techniques should give satisfactory results. Although, the theory and models suggest that it is a straightforward problem. This has been proven to be true in real world applications. Our experiment is a clear case of failure of seismic surface waves methods to detect cavities.

\section{References}

A. Bitri., K. Samyn, and Th. Jacob 2014. Cavity investigation by surface wave tomography and microgravity.

K. F. Graff, 1975 Wave motion in elastic solids, Dover Publications, New York.

N. Gucunski, V. Ganji, and M.H. Maher, 1996. Effects of obstacles on Rayleigh wave dispersion obtained from the sasw test," Soil dynamics and earthquake engineering, vol. 15, no. 4, pp. $223-$ 231.

N. A. Haskel, "The dispersion of surface waves on multilayered media," Bull. Seismol. Soc. Am., vol. 54, no. 2, pp. 627-679, 1953.

Hermann R.B. 1987. Computer Programs in Seismology. Saint-Louis University, USA.

D. Leparoux, A. Bitri, and G. Grandjean, 2000. Underground cavity detection: a new method based on seismic Rayleigh waves," European Journal of Environmental and Engineering Geophysics, vol. 5, pp. $33-53$.

Nasseri-Moghaddam, A., Cascante, G., Hutchinson, J., 2005. A new quantitative procedure to determine the location and embedment depth of a void using surface waves. Journal of Environmental and Engineering Geophysics 10 (1) 51-64.

Park, C.B., Xia, J. and Miller, R.D., 1998. Ground roll as a tool to image near-surface anomaly. Expanded Abstr. $68^{\text {th }}$ Ann. Internat. SEG Mtg., New Orleans: 874-877

Samyn, K., Bitri, A., Grandjean, G. 2013. Imaging a near-surface feature using cross-correlation analysis of multi-channel surface wave data, Near Surface Geophysics, 11, 1-10.

Sloan, S. D., Peterie, S. L., Miller, R.D., Ivanov, I., Schwenk, T. J., and McKenna, R.J., 2015. Detecting clandestine tunnels using near-surface seismic techniques. Geophysics Vol. 80 No. 5 P. EN127-EN135

W. T. Thomson, "Transmission of elastic waves through a stratified solid medium," Journal of Applied Physics, vol. 21, no. 2, pp. 89—93, 1950.

Xia, J., Nyquist, J. E., Xu, Y., Roth, J.S.M., Miller, R.D. 2007. Feasibility of detecting near-surface feature with Rayleigh wave diffraction. Journal of applied geophysics. 62, p 244-253. 